DOI: http://dx.doi.org/10.18309/anp.v1i50.1317

\title{
A VERTIGEM DAS SENSAÇÕES EM “É O SILÊNCIO...”, DE PEDRO KILKERRY
}

\section{THE VERTIGO OF THE SENSATIONS IN “É O SILÊNCIO...”, BY PEDRO KILKERRY}

\author{
Carlos Eduardo Siqueira Ferreira de Souza \\ Pontifícia Universidade Católica de São Paulo, São Paulo, São Paulo, Brasil \\ csouza@pucsp.br \\ Annita Costa Malufe \\ Pontifícia Universidade Católica de São Paulo, São Paulo, São Paulo, Brasil \\ annitacostamalufe@gmail.com
}

Resumo: O artigo propõe uma leitura do poema "É o silêncio...", de Pedro Kilkerry, com o objetivo de enfocar a questão do processo de criação poética aí presente, não somente enquanto tema, mas sobretudo enquanto a própria dinâmica encarnada na escrita. Para tanto, parte-se do conceito de bloco de sensação (afectos e perceptos), proposto por Gilles Deleuze e Félix Guattari, em relação com os conceitos de território e desterritorialização, dos mesmos filósofos, no intuito de compreender o movimento de criação que se materializa no poema. A partir de uma releitura de Kilkerry, busca-se testar a hipótese de que a singularidade de sua poesia resulta não só do tratamento original que confere à linguagem, mas também de sua engenhosidade para reconfigurar esteticamente, à luz do fenômeno da alteridade, o problema da subjetividade.

Palavras-chave: Poesia; Pedro Kilkerry; Território; Sujeito; Sensação

Abstract: The article proposes a reading of Pedro Kilkerry's "É o silêncio...", with the aim of focusing on the issue of the poetic creation process present in the poem, not only as a theme, but above all as the dynamics itself embodied in writing. For this, we start from the concept of block of sensation (affects and percept), proposed by Gilles Deleuze and Félix Guattari, in relation to the concepts of territory and deterritorialization, of the same philosophers, in order to understand the movement of creation that is materialized in the poem. Based on a reinterpretation of Kilkerry poetry, we try to test the hypothesis that not only does the uniqueness of his poetry results from the original treatment he gives to language, but also from his ingenuity to aesthetically reconfigure, in the light of the phenomenon of alterity, the problem of subjectivity.

Keywords: Poetry; Pedro Kilkerry; Territory; Subject; Sensation 


\section{Introdução}

Pedro Kilkerry, figura central da segunda geração do Simbolismo baiano, permanece à margem da literatura brasileira, apesar de alguns esforços empreendidos para a difusão de sua obra por autores como Andrade Muricy e Augusto de Campos ${ }^{1}$. A condição periférica a que sua lírica é relegada resulta da convergência de uma série de fatores, dentre eles o contexto em que produziu sua obra - Bahia, primeiras décadas do século XX - e, em especial, a natureza obscura de sua linguagem. Segundo Andrade Muricy (1952, p. 15), "seu curioso hermetismo à Mallarmé faz dele um longínquo precursor do surrealismo contemporâneo". Conforme Augusto de Campos (1985, p. 30), mesmo nos seus primeiros poemas, quando o poeta ainda se mostrava "ligado aos moldes parnaso-simbolistas da época, adverte-se na sua técnica compositiva um adensamento de linguagem, uma complicação sintática, um arrevesamento metafórico menos comuns". Hermetismo e experimentalismo seriam, dessa forma, traços de modernidade presentes na poesia de Kilkerry, resultantes de um tratamento singular conferido à linguagem, mediante emprego de procedimentos incomuns ao Simbolismo Brasileiro, como a sintaxe irregular, obscura, e a imagem plástica de construção intrincada.

Considerando o contraste entre a relevância de sua poesia e a posição periférica que ocupa no imaginário cultural brasileiro, propomos, neste trabalho, lançar novas luzes à escritura do vate baiano mediante o exame dos processos de subjetivação que singularizam e conservam a potência de sua lírica. Mediante a leitura do poema "É o silêncio...", buscamos testar a hipótese de que tal singularidade resulta não só do tratamento original que Kilkerry confere à linguagem, mas também de sua engenhosidade para reconfigurar esteticamente, à luz do fenômeno da alteridade, o problema da subjetividade, conceito tão desgastado por opiniões formadas nos campos da filosofia e da teoria literária.

Fundamentam teoricamente a leitura proposta algumas personagens conceituais que habitam o pensamento vertiginoso operado por Gilles Deleuze e Félix Guattari, em especial os conceitos a respeito da obra de arte presentes em "Percepto, afecto e conceito" e "Do caos ao cérebro", capítulos de $O$ que é a filosofia? (1990), e a fórmula do ritornelo, tal como desenvolvida em "Acerca do ritornelo", de Mil platôs $(1980)^{2}$. O intuito é experimentar novos acoplamentos conceituais que nos ajudem a investigar a poética de Kilkerry, ao mesmo tempo atualizando e reativando a força de sua proposta.

\section{Poema: ser de sensação}

No início de "Do caos ao cérebro", capítulo que encerra O que é a filosofia? (2010), Gilles Deleuze e Félix Guattari retomam a menção ao tortuoso exercício do pensamento, trabalhado ao longo da obra: "Nada é mais doloroso, mais angustiante do que um pensamento que escapa a si mesmo..." (DELEUZE; GUATTARI, 2010, p. 237). Segundo os autores, as

\footnotetext{
${ }^{1}$ Pedro Militão Kuilkuery (1885-1917) nasceu na Bahia, onde se formou em Direito e atuou como jornalista, desenvolvendo obra poética singular, dispersa em jornais e revistas da época, em especial nos periódicos simbolistas Nova Cruzada e Os Anais. Segundo Jackson de Figueiredo, amigo do poeta, Kilkerry opunha-se a publicar sua obra em livro, mantendo seus poemas de memória ou em rascunhos: "quando os escrevia, era ora nas paredes, ora em trapos de papel ou página de livros, no mais absoluto alheamento à ideia de os publicar" (FIGUEIREDO, 1921, p. 70). A primeira publicação de seus poemas em livro foi realizada por Figueiredo, quatro anos após a morte do poeta, e ocupa o segundo capítulo de Humilhados e luminosos (1921), que abrange a produção de alguns escritores baianos do início do século XX. Em 1952, Kilkerry foi incluído por Andrade Muricy no Panorama do movimento simbolista brasileiro (1952), entretanto, sua obra só ganhou o devido destaque em 1970, com a primeira edição de ReVisão de Kilkerry (1985), organizada por Augusto de Campos, responsável por apresentar, em um só volume, poemas e crônicas do poeta, além de perfis biográficos e ensaios de autores diversos sobre sua poesia.

${ }^{2}$ Indicadas aqui as datas de publicação original dessas obras.
} 
ideias seriam "variabilidades", "velocidades infinitas" que, nascidas no caos, aparecem e desaparecem, precipitando-se umas sobre as outras, incontroláveis. Para se preservar do perigo sempre iminente da perda de si, o sujeito pensante recorre a "regras protetoras, semelhança, contiguidade, causalidade", mediante as quais seria capaz de ordenar seus pensamentos, agarrando-se, dessa forma, a opiniões prontas. Como forma de se proteger do caos, portanto, opiniões são formadas, amparadas pelas sensações, que atuam como garantia de um acordo, colocando em aparente conformidade as coisas e os pensamentos que lhe são correspondentes.

O verdadeiro ato de pensar, para esses filósofos, demandaria interferir sobre essa dinâmica, no sentido de se combater o sistema de opiniões formadas, arriscando-se no caos, sem se deixar, ao mesmo tempo, ser completamente submergido por ele. É dessa forma que, mesmo diante dos perigos que emanam do caos, arte, ciência e filosofia encontram uma saída para o exercício do pensamento. Lidando com o caos e, simultaneamente, erigindo planos que o organizam provisoriamente e dele retiram aquilo que permite a perpétua criação e mobilidade dos sentidos, essas seriam, para eles, as três atividades criadoras dos seres humanos. É assim que o artista, ao invés de lutar ou se proteger das forças do caos, nele mergulha para daí poder extrair novas sensações, das quais se ergue a obra de arte: "O artista traz do caos variedades, que não constituem mais uma reprodução do sensível no órgão, mas erigem um ser do sensível, um ser da sensação, sobre um plano de composição, anorgânica, capaz de restituir o infinito" (DELEUZE; GUATTARI, 2010, p. 238-239).

Nesta concepção, o artista - o poeta, em nosso caso - é um pesquisador de novas sensações, de novos "afectos" e "perceptos": seu objetivo é compor um plano em que esses seres de sensação ganham vida própria, tornando-se "seres autônomos e suficientes" (DELEUZE; GUATTARI, 2010, p. 218). Deleuze e Guattari dirão que os afectos e perceptos são as sensações compostas esteticamente, ou seja, são afecções e percepções que se descolaram dos sujeitos e dos objetos, tornaram-se independentes da situação vivida em que se originaram e ganharam autonomia. Aqui, a proposta é de se pensar uma arte livre das determinações subjetivistas e objetivistas, livre das memórias, opiniões e, ainda, de determinismos culturais. O que seria importante para a obra, o poema, é essa composição de blocos de sensação que "se mantêm em pé" sozinhos 3 , que erigem um movimento a comemorar o movimento perpétuo e ininterrupto da vida, sempre renovado a cada época e leitura.

Nessa visão, o poema seria, portanto, um composto de perceptos e afectos que proporcionam uma visão renovada, contra as certezas e os clichês. Um composto de sensações desestabilizadoras, que atuariam no corpo (do leitor) a cada vez que o poema é lido, relido, acionado. É justamente essa potência desestabilizadora das convenções que se manifesta na poesia de Pedro Kilkerry e é encenada no poema a seguir:

\footnotetext{
É o silêncio, é o cigarro e a vela acesa. Olha-me a estante em cada livro que olha. E a luz nalgum volume sobre a mesa... Mas o sangue da luz em cada folha.

Não sei se é mesmo a minha mão que molha A pena, ou mesmo o instinto que a tem presa. Penso um presente, num passado. E enfolha A natureza tua natureza.

Mas é um bulir das cousas... Comovido
}

\footnotetext{
3 “A obra de arte é um ser de sensação, e nada mais: ela existe em si”; um composto que deve "manter-se em pé sozinho [...] conservar-se em si mesmo" (DELEUZE; GUATTARI, 2010, p. 214). A obra constitui um monumento, mas que não comemora o passado e, sim, dizem eles, um: "bloco de sensações presentes que só devem a si mesmas sua própria conservação" (DELEUZE; GUATTARI, 2010, p. 218).
} 
Pego da pena, iludo-me que traço

A ilusão de um sentido e outro sentido.

Tão longe vai!

Tão longe se aveluda esse teu passo,

Asa que o ouvido anima...

E a câmara muda. E a sala muda, muda...

Afonamente rufa. A asa da rima

Paira-me no ar. Quedo-me como um Buda

Novo, um fantasma ao som que se aproxima.

Cresce-me a estante como quem sacuda

Um pesadelo de papéis acima...

\author{
E abro a janela. Ainda a lua esfia \\ Últimas notas trêmulas... O dia \\ Tarde florescerá pela montanha. \\ E oh! minha amada, o sentimento é cego... \\ Vês? Colaboram na saudade a aranha, \\ Patas de um gato e as asas de um morcego. \\ (CAMPOS, 1985, p. 43)
}

Em "É o silêncio...", a experiência do momento da criação poética revela-se ao mundo sem perder seu caráter enigmático. À arquitetura sonora do poema, erigida em paronomásias e cadeias aliterativas $(m$ e $p$ ), soma-se um rico trabalho de construção de imagens e de inversões da lógica sintática: no lugar de um sujeito percepiente que olha as coisas, são as coisas que passam de predicado a sujeito da ação, percebendo, olhando o sujeito. Rompendo com a lógica formal da linguagem cotidiana e operando uma espécie de metamorfose da realidade apreendida sensorialmente, Kilkerry inscreve no corpo do poema a experiência de um sujeito lírico em devir que, inserido em uma "câmara muda", imerso no instante da criação poética, espreita as percepções e afecções por ele experimentadas nesse acontecimento. Dessa experiência, ele parte para compor o poema, que parece ser escrito, justamente, na imagem de mutação ("mudo") que surge na segunda estrofe. Se quisermos, é como se, nessa transmutação, que é a própria escrita do poema, as percepções e afecções inicialmente subjetivas adquirissem uma existência estética, sob a pluma do poeta: emergem, assim, perceptos e afectos constitutivos dos blocos de sensações que promovem o processo escritural.

Se, como propõem Deleuze e Guattari (2010, p. 193), um poema, enquanto obra de arte, é esse ser de sensação, "composto de perceptos e afectos", vale insistir nas imagens que, apreendidas sensorialmente pelo sujeito lírico, consolidam, no movimento desse poema, o instante da criação poética: à noite, o poeta, instalado solitariamente em seu escritório (câmara muda), rodeado por componentes (cigarro, vela acesa, estante, livros, pena etc.) que territorializam ${ }^{4}$ esse seu espaço, é afetado pelo contato sensorial entre seu corpo e tais objetos, sofrendo sutis mas perturbadoras dissociações que atravessam tanto sujeito quanto objetos, lançados a um corpo a corpo energético: eu lírico e mundo deixam de ser entidades definidas, delimitadas, desterritorializando-se mutuamente. Em uma dinâmica regida pelo signo da alteridade, não é o sujeito quem olha a estante e os livros que nela estão contidos, mas a estante é quem olha "em cada livro que olha". Poderíamos dizer, com Deleuze e Guattari, que ocorre aqui um devir não-humano do homem, uma percepção que extravasa as experiências humanas e fabula um modo inusitado de olhar e sentir:

\footnotetext{
${ }^{4}$ Temos em vista aqui os conceitos de "território" e "desterritorialização", tais como desenvolvidos em Mil platôs, por Deleuze e Guattari (2012), conforme procuraremos explicitar mais adiante.
} 
Os perceptos podem ser telescópios ou microscópios, dão aos personagens e às paisagens dimensões de gigantes, como se estivessem repletos de uma vida à qual nenhuma percepção vivida pode atingir (DELEUZE; GUATTARI, 2010, p. 222).

Nesse "bulir das cousas" (sic) que atravessa o silêncio da experiência vivida, simultaneamente ao ato ilusório de escrever ("iludo-me que traço/A ilusão de um sentido e outro sentido"5), a matéria sonora (passo aveludado, asa que anima o ouvido) invade o espaço, afetando a câmara de forma ambígua. Podemos seguir Augusto de Campos, quando enfatiza a ambivalência trazida pela palavra muda, empregada como verbo e adjetivo ("E a câmara muda. E a sala muda, muda...”): "a sala muda e está muda, enquanto o poeta, nas antecâmaras do poema, aguarda a irrupção do próximo som" (CAMPOS, 1985, p. 44), um rufar afônico que se aproxima da sala e provoca a transfiguração do sujeito em um "Buda novo", em "um fantasma ao som que se aproxima". Importante salientar que o poeta não se atém a abordar de modo referencial o impacto que os sons exercem sobre o eu lírico, pelo contrário, é evidente a atuação de Kilkerry no plano de composição estética, criando blocos de sensações, constituídos por toda uma gama de afectos e perceptos que tornam sensível a dimensão sonora da palavra, como bem atesta a complexa articulação de assonâncias, aliterações e paronomásias, procedimentos relativos ao extrato fônico do poema. ${ }^{6}$ Essas sonoridades são experimentadas pelo corpo do leitor em articulação com as imagens de cunho mais visual, que entrelaçam os diferentes sentidos de modo a produzir a sensação, enquanto esse ser que se autonomiza da dimensão representativa da linguagem.

Na penúltima estrofe, após uma pausa marcada por uma linha tracejada, um novo bloco de sensações prepara o fechamento da experiência (e do poema): uma fenda surge no espaço fechado e silencioso da câmara, uma janela é aberta, lançando o sujeito para o instante indeterminado entre a noite e o dia, uma madrugada que parece esgarçar-se entre a lua prestes a desaparecer e a manhã que hesita em nascer. Destaca-se a presença do enjambement que faz "O dia" operar, no plano linguístico, tanto como predicado, objeto tecido pela música lunar, quanto como sujeito que se demora a aparecer: "E abro a janela. Ainda a lua esfia/ Últimas notas trêmulas... O dia/ Tarde florescerá pela montanha".

De forma enigmática, o poeta encerra seu relato, valendo-se de mais um pequeno bloco de sensações que, diz o poema, "colaboram na saudade", criando a partir desse sentimento um inusitado afecto que parece transbordar do material vivido. As imagens surgem como um não senso: aranha, patas de gato e asas de morcego. Imagens que constituem espécies de resíduos que irrompem na consciência do eu lírico como ingredientes de uma fórmula mágica da poesia, associando-se às matérias sonoras e praticamente inaudíveis (passo "aveludado"; "asa que o ouvido anima") percebidas durante a criação, impelindo o sujeito à composição do texto.

Dois momentos distintos manifestam-se, portanto, no poema: primeiramente, nas duas primeiras estrofes, encerrado na câmara muda, o poeta escreve sob o impacto das sensações que se apresentam a sua volta e que o poema transforma em perceptos e afectos; em seguida, nas duas últimas estrofes, o eu lírico experimenta o momento imediatamente posterior à criação do poema, durante o qual busca, aparentemente, retornar a um estado mais familiar, a uma conexão mais reconhecível com a realidade, deparando-se, entretanto, com um mundo transfigurado, insubmisso à razão, afinal, se "a lua esfia suas últimas notas trêmulas", o dia não deveria florescer tarde "pela montanha".

Interessante observar que Kilkerry, nesse poema, não se ocupa da poesia em sua

\footnotetext{
5 No poema, o termo "sentidos" assume caráter ambíguo, podendo se referir tanto à dimensão material da experiência percebida sensorialmente, quanto à dimensão virtual, informe, abstrata, que se manifesta fora da linguagem, da razão.

${ }^{6}$ A respeito da rica textura sonora de "É o silêncio...", ver Campos (1985, p. 43-44).
} 
dimensão histórica ou literária, mas procura observar e figurar ${ }^{7}$ a criação poética enquanto experiência inusitada de um corpo em pleno contato com o mundo. Para o poeta, a radicalidade da experiência afeta tanto o mundo quanto o próprio sujeito que, como um fantasma, observa sua própria dissolução, ainda que sem perder-se de vista, e dela parte para a experiência de escrever.

\section{Ritornelo}

Ao evidenciar os processos de transformação que reconfiguram a existência do sujeito e do mundo, Kilkerry parece efetuar no poema um movimento próximo ao que Deleuze e Guattari (2012) formularam acerca do conceito de "ritornelo" em Mil platôs, quando descrevem a dinâmica da constituição de territórios que marcaria tanto a vida, quanto a arte ou a filosofia. A dinâmica do ritornelo, para os filósofos, estaria presente nos animais, bem como na constituição das subjetividades e no funcionamento dos grupos, das instituições, das culturas. Seria, em suma, um modo de nos aproximarmos de um movimento implicado nas relações humanas, nos seus diversos níveis, mas que pode narrar bem a constituição do plano de composição da arte. Trata-se da necessidade de, confrontado com o caos ou com a falta de forma e contornos, criar-se um pequeno eixo em torno do qual uma periodicidade, uma estabilidade ou constância possa começar a existir. É do caos, da instabilidade, então, que uma criança cantará no escuro para se fazer uma casa e apaziguar o medo, do mesmo modo que, para demarcar seu território, um pássaro poderá virar as folhas em torno de uma árvore e construir seu ninho. A arte, do mesmo modo, começa com a eleição de um eixo, em torno do qual algo gira: convocam-se os elementos, os materiais, procedimentos, até que se tem um pequeno lugar, com seu ritmo específico e suas membranas que delimitam um dentro e um fora. É o território, que se cria fragilmente em torno de um centro até que, por alguma força que o esgarça, suas paredes cedem, ele se abre, uma linha de fuga se faz e se estabelece um novo centro, que, por sua vez, servirá como novo eixo de um novo território: desterritorizalizamo-nos. Trata-se dos três aspectos do ritornelo, a saber: caos, terra e cosmos. Ou: eleger um centro em meio ao caos, girar em torno dele e escapar.

Vale dizer que, para Deleuze e Guattari (2012), o território comporta sempre fugas, margens e comunicação com outros territórios, com os quais ele troca e se modula, sem cessar. Ou seja: um território não é um sistema fechado, cristalizado. Pensar a dinâmica do ritornelo implica, para os filósofos, a necessidade de se pensar uma dinâmica do constante devir - do deslocamento perpétuo que constitui tanto a vida orgânica quanto a vida de uma obra de arte. O ritornelo fala, assim, de uma repetição da diferença, de uma repetição não circular, que colocará sempre em jogo o acaso e a necessidade de linhas de fuga; uma dinâmica de ciclos descentrados, que sempre se deslocam e asseguram a irrupção de novas conexões - o que define a própria dinâmica da vida e do vivo, assim como a dinâmica da terra e dos elementos inanimados. ${ }^{8}$

O poema "É o silêncio..." parece-nos emblemático ao dramatizar, em sua composição, o próprio processo de criação (e autocriação) e, ao fazê-lo, incorporar exemplarmente essa dinâmica do ritornelo, que encarna a repetição da diferença. No primeiro verso do poema, as forças do caos parecem mantidas no exterior da morada criada pelo poeta,

\footnotetext{
${ }^{7}$ Augusto de Campos (1985, p. 42) dirá que "É o silêncio..." "mostra o poeta dono de uma extrema limpidez e pureza de dicção, atento, fenomenologicamente, ao 'bulir das coisas"”.

${ }^{8}$ Nos limites deste artigo não teríamos como explorar a complexa abordagem conceitual do ritornelo em Deleuze e Guattari, desenvolvido em "Acerca do ritornelo" (2012), platô 11 de Mil platôs; cabe-nos apenas assinalar a abrangência desse conceito para seu pensamento, implicando em toda uma concepção de tempo, relacionada com o projeto mais amplo da filosofia da diferença de Deleuze, iniciada em sua obra Différence et répétition (1968) na qual é explicitada a ideia de um tempo da diferença, que coloca em evidência o tempo do futuro e a irrupção do novo, que marcará toda sua filosofia e, consequentemente, seu pensamento com a arte e a literatura.
} 
morada constituída por componentes - silêncio, cigarro e vela acesa - que, por força do hábito de escrever, desenham o território da escritura. Tais imagens, combinadas a outras distribuídas nos outros versos (estante, livros, folhas, papéis, pena, mão do poeta), emergem como perceptos que parecem sustentar, como um bloco de sensações, o território mais ou menos estável de um processo escritural; trata-se de componentes que, à primeira vista, pertenceriam ao ritornelo da terra (a morada, o em-casa), envolvendo a câmara, local aparentemente seguro da criação poética. No entanto, lembram Deleuze e Guattari (2012, p. 122), "foi preciso traçar um círculo em torno do centro frágil e incerto, organizar um espaço limitado". O eu lírico poeta: centro frágil e incerto, prestes a deslocar-se a cada instante, protegido por forças que erguem e sustentam sua morada: uma câmara silenciosa, muda, territorializada pelos componentes que organizam o espaço da criação. Na morada, "as forças do caos são mantidas no exterior tanto quanto possível, e o espaço interior protege as forças germinativas de uma tarefa a ser cumprida, de uma obra a ser feita" (DELEUZE; GUATTARI, 2012, p. 122).

Para que a tarefa seja cumprida e a gênese do poema se efetue, certas forças - linhas de fuga, de errância - afetam o eu lírico, formando um composto de afectos dissonantes, desterritorializando o espaço habitual da criação literária, "como se o próprio círculo tendesse a abrir-se para um futuro, em função das forças em obra que ele abriga" (DELEUZE; GUATTARI, 2012, p. 123). Trata-se dos instantes em que o momento solitário do fazer poético é arrebatado pela carga sensorial provocada pelo movimento das coisas ("bulir das cousas"). Afinal, para que a obra se realize, os elementos que constituem o plano de composição devem tornar-se expressivos, configurando sensações. É o momento em que se faz o território; os elementos, procedimentos e materiais, cessam de se ligar por relações funcionais e criam uma dimensão, um "em torno" que constitui uma casa. Para que a criação se efetue, para que "a asa da rima" deixe de pairar no ar e anime o poema, os elementos que constituem o plano de composição técnica - nesse caso, silêncio, cigarro, vela acesa, estante, livros, folhas, papéis, pena, mão do poeta - devem superar sua inércia, suas funções corriqueiras, e subir ao plano de composição estética, constituindo novas relações, novas conexões móveis. As afecções experimentadas pelo poeta em ações determinadas - olhar a estante e os livros; perceber o volume de folhas na mesa por meio da luz emanada pela vela acesa; molhar a pena no tinteiro; traçar a ilusão de sentidos - transbordam a experiência do sujeito e eclodem como afectos ou "devires não humanos do homem" (DELEUZE; GUATTARI, 2010, p. 200). Isso ocorre porque o sujeito desfaz-se, perde-se ou dilui-se na paisagem-câmara, a ponto de anular a dicotomia sujeito-objeto, assomando devires. O sujeito devém estante, livros, papéis, luz. Algo passa do sujeito aos objetos e, inversamente, criam-se zonas de indeterminação, de indiscernibilidade, "como se coisas, animais e pessoas [...] tivessem atingido, em cada caso, este ponto (todavia no infinito) que precede imediatamente sua diferenciação natural" (DELEUZE; GUATTARI, 2010, p. 205).

Aqui está compreendido conjuntamente o terceiro aspecto do ritornelo, aquele que lança poeta e poema (e leitor) "ao encontro de forças do futuro, forças cósmicas" (DELEUZE; GUATTARI, 2012, p. 123). Abre-se uma janela para a passagem da noite para o dia, revelando um bloco final de sensações (aranha, patas de gato, asas de morcego), encerrando a composição, lançando-a para o infinito das conexões a darem-se na leitura-performance do poema, a cada vez e momento. O terceiro aspecto do movimento do ritornelo, a fuga, a fresta que faz o território recém constituído já se dar em abertura a novos territórios que o margeiam, faz parte do próprio modo de ser do plano de composição da arte. Ele é um plano que explicita sua mobilidade, sua constante abertura aos elementos que o desestabilizam. Daí ser o poema essa casa ao mesmo tempo frágil e potente, capaz de provocar desterritorializações inesperadas. Conforme vemos no conceito de ritornelo, assim, é preciso considerar os três aspectos (eleger um centro, girar em torno dele e escapar) como um só e 
mesmo movimento, simultâneo, e não como três etapas sucessivas. O ritornelo do poema compreende, assim, esse ciclo e nos convida a participar dele, experimentalmente, corporalmente.

\section{Considerações finais}

Em "É o silêncio...", sujeito e mundo emergem dos blocos de sensações não como dados autônomos e independentes, mas como modos, possibilidades de existência que se configuram nas tramas da alteridade. Não se trata de um sujeito diante de um objeto, mas de um eu lírico que espreita com o corpo (sem órgãos), corpo de sensações, sua própria existência em dissolução e transformação, decorrente do contato com os blocos de sensações que lhe afetam no instante da criação.

No lugar de uma arte poética, de uma reflexão de ordem teórica ou programática sobre a poesia, Kilkerry erige a materialização da experiência criativa, expressa como transfiguração de perceptos e afectos sofridos no instante exato em que a obra se apresenta, instante que não se deixa assimilar intelectualmente, já que não é da ordem do inteligível e só pode ser apreendido, por meio de seus resíduos perceptivos, como sensação que afeta o corpo. Ao poeta, parece-lhe interessar a dimensão incorpórea, misteriosa, enigmática do processo criativo, no entanto, paradoxalmente, do mistério restam vestígios concretos, fragmentos de suas percepções e afecções, transmutados em sensações estéticas.

Todo o esforço do eu lírico, portanto, reside em transfigurar os afectos e perceptos que transbordam da face mística, ilusória, inapreensível da experiência de criação poética em blocos de sensações que, como seres novos, nascidos de uma exacerbação da experiência, permitem ao leitor aproximar-se do caráter quase místico do fenômeno. Kilkerry, ao lutar bravamente com as forças do caos, inverte ou subverte o sistema de opinião corrente sobre o ato de criação literária, proporcionando a experiência violenta de uma poética renovada, em direção à poesia moderna.

\section{Referências}

Campos, Augusto de. ReVisão de Kilkerry. 2. ed. São Paulo: Brasiliense, 1985.

Deleuze, Gilles. Différence et répétition. Paris: P.U.F., 1968.

Deleuze, Gilles; Guattari, Félix. O que é a filosofia? 3. ed. Tradução de Bento Prado Jr. e Alberto Alonso Muñoz. São Paulo: Editora34, 2010.

Deleuze, Gilles; Guattari, Félix. “Acerca do ritornello”. In: Deleuze, Gilles; Guattari, Félix. Mil Platôs: capitalismo e esquizofrenia 2. v. 4. 2. ed. Tradução de Suely Rolnik. São Paulo: Editora34, 2012.

Figueiredo, Jackson de. "Pedro Kilkerry". In: Figueiredo, Jackson de. Humilhados e luminosos. Rio de Janeiro, Porto: Annuario de Brasil, Renascença Portuguesa, 1921.

Muricy, Andrade. Panorama do movimento simbolista brasileiro. vol. II. Rio de Janeiro: Instituto Nacional do Livro, 1952.

Muricy, Andrade. "Presença do Simbolismo". In: Coutinho, Afrânio (dir.). A literatura no Brasil. vol. 4. São Paulo: Global, 2002, p. 399-488. 